\title{
@stephanjoubert: Tweeting the gospel aphoristically
}

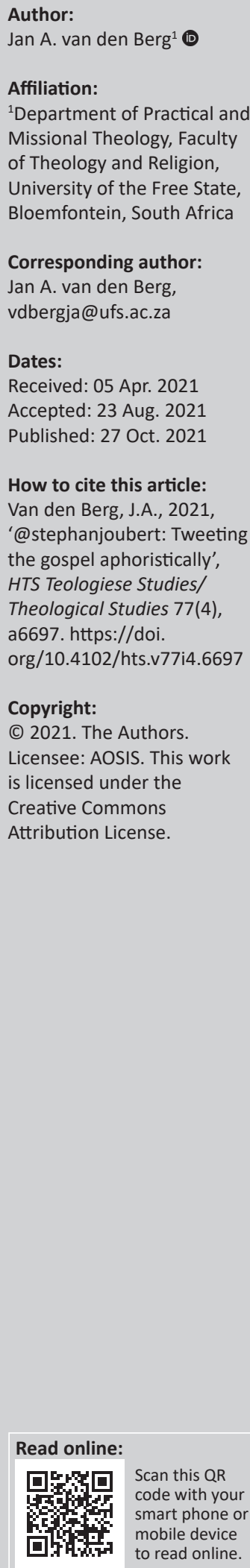

This contribution focusses on some of the digital theological expressions of Stephan Joubert from an auto-ethnographic angle. Orientating from a practical theology perspective, I have chosen the social media platform Twitter, and more specifically the @stephanjoubert domain, as source to chart some significant tweet expressions for the purpose of describing the character and value of an aphoristic theology. In order to do so, I have used some randomly selected tweets of Stephan Joubert, spanning the period 2020-2021, which express aspects of a relevant contemporary ecclesiology. Against the backdrop of the disastrous impact of the COVID-19 pandemic as well as some important dates on the Christian calendar (Easter and Christmas), I specifically emphasise the significance of the formulation of an aphoristic theology using amongst other markers of simplicity, contextuality and relevance.

Contribution: I conclude the reflection with some critical-evaluative remarks on the significance of aphoristic expressions for the development of a meaningful contemporary ecclesiology and theology.

Keywords: aphorism; practical theology; auto-ethnography; Twitter; tweets; @stephanjoubert.

\section{Appreciation}

In 1989, I was a student in Theology when I met Stephan Joubert for the first time. Already then, he made an ineffaceable impression on me. Besides the excellent professional knowledge that he conveyed as lecturer, his humility and sincere interest in each one of his students struck me in particular. During my congregational ministry, I took note of Stephan's development of the e-church and the specific way in which he made a visionary and contemporary contribution to a modern and context-sensitive ministry. Years later, we crossed paths again in the Department of Practical and Missional Theology at the University of the Free State. With his appointment as extraordinary professor in Contemporary Ecclesiology, I got to know him in a special way as both a colleague and a friend. Stephan is always willing to invest in other people's lives by way of valuable contributions. It is with great appreciation that I would like to dedicate this contribution to my friend and colleague, Stephan Joubert.

\section{Summary}

In this contribution, I focus, from an auto-ethnographic angle, on some of the digital theological expressions of Stephan Joubert. Orientating from a practical theology perspective, I choose the social media platform Twitter, and more specifically the @stephanjoubert domain, as source to chart some significant tweet expressions for the purpose of describing the character and value of an aphoristic theology. In order to do so, I use some randomly selected tweets of Stephan Joubert, spanning the period 2020-early 2021, which express aspects of a relevant contemporary ecclesiology. Against the backdrop of the disastrous impact of the COVID-19 pandemic as well as some important dates on the Christian calendar (Easter and Christmas), I specifically emphasise the significance of the formulation of an aphoristic theology using amongst other markers of simplicity, contextuality and relevance. I conclude the reflection with some critical-evaluative remarks on the significance of aphoristic expressions for the development of a meaningful contemporary ecclesiology and theology.

Note: Special Collection: From timely exegesis to contemporary ecclesiology: Relevant hermeneutics and provocative embodiment of faith in a Corona-defined world - Festschrift for Stephan Joubert, sub-edited by Willem Oliver (University of South Africa). 


\section{@stephanjoubert - Introduction}

stephan joubert
@stephanjoubert
inve biggest coup in history happened when heaven
through Jesus. We become part of this unstoppable
new reign of God when we follow Him
7:17 AM - Mar 21, 2021 - Twitter for iPhone

Source: @stephanjoubert 2021b:n.p.

FIGURE 1: Kingdom of God.

In my own life, seeking meaningful relevance is important and essential for purposeful direction in my work. For this reason, I agree with the expression that theology is not a noun, but a verb (Hendriks 2004:24). To me, Stephan Joubert's life and work is an outstanding example of seeking to embody meaningful theological relevance and of ways to do so. Although one could describe this in several ways, I deemed it fit to use Stephan's ${ }^{1}$ own Twitter account, along with some tweets from his computer's or cell phone's test board, as an example of a contextual theological relevance which I consider significant. Take, for instance, Figure 1 at the beginning of the subsection in the article. It is surprising that a metaphor is used paradoxically to introduce the reader, in an accessible way, to a specific theological reality and its significance. The use of associative networks of meaning (Müller \& Maritz 1998:64), derived from the use of the central metaphor of a coup d'état, presents God's kingdom, sovereignty and the other reality it offers, in both an imaginative and a terse way in no more than 34 words. Although the tweet is dated 21 March 2021, the wording bears a specific timeless character.

Arising from the introductory perspectives, I will subsequently and on the basis of an underlying and sublime autoethnographic description, provide an overview of the value and significance of aphoristic theology that is embodied in Stephan Joubert's tweets. On the basis of my own brief reflections from my own life as already presented at the start of the article, I will present autoethnographic fragments as orientation and basis for the article's structure. As indicated by Holt (2003:18): 'Autoethnography is a genre of writing and research that connects the personal to the cultural, placing the self within a social context'. This connection between my own personal search for relevance and the manifestation of such significance in the tweet practice of Stephan Joubert is described in this contribution. This research endeavour connects well with the observation by Gopnik (2019):

We don't absorb aphorisms as esoteric wisdom; we test them against our own experience. The empirical test of the aphorism takes the form first of laughter and then of longevity, and its

1.Sprouting from the autoethnographical character of the research, articulating strong undertones of a personal relationship with Stephan Joubert, I prefer to use the first name of 'Stephan' when referring to him. confidential tone makes it candid, not cynical. Aphorisms live because they contain human truth.... (n.p.)

The description is composed of three parts: The first orienting section provides an overview of the nature of the enquiry that is addressed in the contribution. An ensuing second subsection briefly shows the use and meaning of the aphorism. A final subsection provides reflective remarks on the practice of formulating an aphoristic (Twitter) theology, sprouting and backed by examples from Stephan's own tweets.

\section{@stephanjoubert - In search of an aphoristic theology}

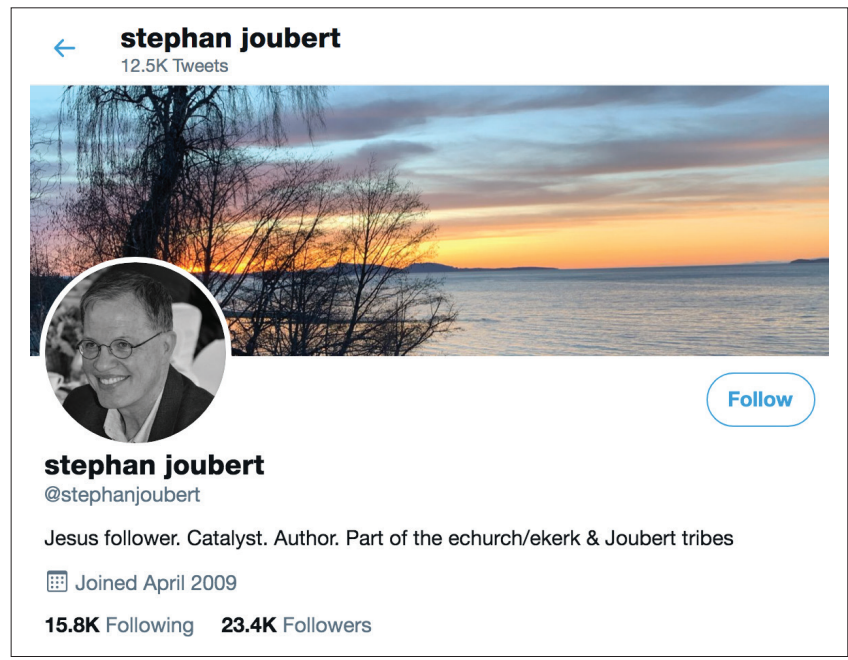

Source: @stephanjoubert 2021a:n.p.

FIGURE 2: Twitter profile of Stephan Joubert.

Figure 2 portrays the Twitter profile of Stephan Joubert. Besides the remarkable use of autobiographic markers to describe himself ('Jesus follower; Catalyst, author, Part of the echurch/ekerk \& Joubert tribes'), there is also an indication of his own connectivity in the digital world. Not only are there nearly 24000 followers, but he himself also follows nearly 16000 other Twitter profiles with roughly 12500 tweets, created from his account. Statistics show that Stephan bears a specific presence and relevance, and that it is easy to communicate in the digital world. This reflection raises the question as to the basis of this research, namely the style and content of meaning and relevant communication in the digital world.

In search for theological relevance, I am privileged to often be able to discuss this issue with Stephan. ${ }^{2}$ During informal

2.In previous research (Van den Berg 2018:n.p) I have already indicated that Stephan has signaled Twitter as his primary means of social interaction in cyberspace because of its simplicity and the 140-character limitation (later adjusted to 280 characters). Stephan had previously with the following personal explanation, 280 characters). Stephan had previously with the following personal explanatio

On Twitter people are forced to tweet their information, opinions, truths and ideas briefly, yet with great clarity and relevance. Twitter forces those using this form of social Endless ramblings of egotists, attention, etc, stand no chance here of attracting or keeping attention here on the long run. It's all about social connectivity and belonging here. Marshall McLuhan taught us the medium is the message. Twitter forces us to rethink our faith on the cyber squares amongst non-religious people and non-professional 
and personal talks with him, he often told me about books that have a specific meaning for him. During one of these talks, he told me about the book entitled" "The laws of simplicity' (Maeda 2006) by the designer and technology expert John Maeda. Stephan explained that, on so many levels in his own life, research and ministry, he aligns with Maeda's endeavour to 'achieving simplicity in the digital age ....' (Maeda 2006:n.p.). As many times before, I followed-up on Stephan's reference to Maeda's book and found the indication of the following 10 laws on the basis of which 'simplicity' can be developed (Maeda 2006:n.p.):

1. Reduce: The simplest way to achieve simplicity is through thoughtful reduction.

2. Organise: Organisation makes a system of many appear fewer.

3. Time: Savings in time feel like simplicity.

4. Learn: Knowledge makes everything simpler.

5. Differences: Simplicity and complexity need each other.

6. Context: What lies in the periphery of simplicity is definitely not peripheral.

7. Emotion: More emotions are better than less.

8. Trust: In simplicity we trust.

9. Failure: Something can never be made simple.

10. The One: Simplicity is about subtracting the obvious, and adding the meaningful.

The meaning of the 10 principles of 'simplicity', as a possible lens on the formulation, functioning and relevance of tweets, allows me to further develop the contribution. In this orientation to the research, important multidisciplinary perspectives are embodied, with amongst others more aspects from design studies, information technology, as well as psychology and practical theology, that are linked to each other.

On account of my personal talks with Stephan, my reading of Maeda's book and my reflecting thoughts on his work and ministry, I have decided to dedicate this article, as part of this Festschrift volume, to how a tweet can possibly express the creation and functioning of a simple aphoristic theology. Mindful of the nature of the contribution and true to the nature of a practical-theological description, I have considered Stephan's practice of tweeting from his account '@stephanjoubert', in order to reflect thereon from both literature and theory. Arising from this reflection, this praxis is then documented in the article on the basis of an autoethnographic reflection.

\section{@stephanjoubert - Finding an aphoristic theology}

The social media platform Twitter uses a restricted number of characters and is the ideal space to develop an aphoristic (footnote 2 continues)

followers of Jesus. It could even force that age-old institution called the church out of the 'safe' space of irrelevant meetings to encounters with present-day issues and questions. Hopefully, a new generation of young marketplace theologians will also rise up to become our mentors, coache and teachers in this fascinating new digitally connected world. Monologues in cyberspace, long sermons; naming and shaming of others in the name of God, etc, just won't survive here. Neither will long discussions about theologica dogmas and local church matters fly here. It's all about relevant connectivity now, not only about more religious information (Joubert 2014:n.p.). theology. This implies that maxims about God can also be tweeted, using a restricted number of characters and words. In recognising that concrete practices are important for a practical-theological description, it would be obvious to examine the @stephanjoubert domain on Twitter. In previous research, I pointed out how Stephan uses his Twitter account efficiently. ${ }^{3}$ In this contribution, I would like to practically focus especially on the aphoristic nature of his tweets and how this not only contributes to the creation of an aphoristic theology, but also expresses in a specific way a contemporary ecclesiology that is embodied in contextuality and relevance. In describing this practice, a practical theological orientation true to its character, is charted from a reflection on praxis (Browning 1991:41).

\section{@stephanjoubert - Personal ... but general}

Psychology and the study of spirituality widely accept the truth that whatever is most personal is also most common. In the famous words of Carl Rogers, later popularised by Henri Nouwen, those aspects which are highly personal are most generally embodied (Nouwen 1976:16). In order to make a difference, my own yearning to communicate efficiently, audibly and comprehensibly was and is certainly one of my greatest needs. Some time ago already, I discovered that people have turned a deaf ear to long and detailed arguments that do not have a personal appeal. They would rather look at and listen to short, lively and expressive maxims (aphorisms). From personal experience, I am convinced that a restricted number of characters in a single sentence have more personality and character than detailed and clinical dusty volumes. Taking into account the central research drive in the article, namely the endeavour to describe the use of the aphorism, in a simplistic way, to communicate a relevant theology and ecclesiology, the following empirical strategy was followed.

Mindful of the important role of exploring, describing and interpreting praxis in practical theology, I use a few randomly selected tweets of Stephan Joubert from 2020 to 2021. Except for the drastic role played by the COVID-19 pandemic over the past year and taking this into account for mining some contextual relevant tweets, I have also examined a few of Stephan Joubert's tweets on some of the most important festivals, namely Christmas and Easter. In my discussion of some of these tweets, I present a brief hermeneutic and personal reflection on their contextual foundation. It is notable that all the tweets are not presented a-historically; they are deeply embedded in a specific concrete time and space. This contextual foundation also includes a personal dimension. I cannot sketch a landscape without placing myself into the picture. This implies the formulation of a personal contextual description that is significant for individuals (in the case of Stephan Joubert), and for many others. Stephan Joubert's tweet, dated 25 March 2020, on the eve of the start of the lockdown period in South Africa, can be viewed as a good example of such a contextually sensitive expression.

3.Please see my doctoral thesis titled 'Tweeting God: A practical theological analysis of the communication of Christian motifs on Twitter' (Van den Berg 2018). 
Living respectfully in a time of Corona:

* Paying respect is a formal duty

* Showing respect is an outward gesture

* Earning respect is self-serving

* Living respectfully is the Jesus-way

8:05 AM $\cdot$ Mar 25, $2020 \cdot$ Twitter for iPhone

Source: @stephanjoubert 2020b:n.p.

FIGURE 3: Living respectfully at the time of corona.

It is generally accepted that the COVID-19 pandemic has reformulated our world. New usages and values such as, amongst others, the compulsory wearing of face masks, the maintenance of social distance, and new travel arrangements are some of the examples of such changes. Although governments manage these changes multinationally, their implication is very personal. In his tweet dated 25 March 2020 , Stephan focuses on the topic of respect, in the run-up to the start of a high level of restrictions at the beginning of the pandemic. This implies concretely embodied in that, if I wear my face mask, I do so as a sign of respect for others. As such, wearing a face mask can become an expression of individual lived spirituality (Figure 3).

\section{@stephanjoubert - The formulation of an aphoristic Twitter theology}

\section{A very short introduction to the aphorism}

The aphorism has evolved and endured across centuries and in various cultures as well as in religious and literary traditions. As Hui (2019), has indicated in his book titled: 'A theory of the aphorism, From Confucius to Twitter':

As a basic unit of intelligible thought, this microform has persisted across world cultures and histories, from Confucius to Twitter, Heraclitus to Nietzche, the Buddha to Jesus. Opposed to the babble of the foolish, the redundancy of bureaucrats, the silence of mystics, in the aphorism nothing is superfluous, very word bears weight. Its minimal size is charged with maximal intensity ... These aphorisms have an atomic quality-compact yet explosive. (n.p.)

In this subsection, my aim is to provide a very short overview on the characteristics of the aphorism. I would very often when referring to an aphorism get a puzzled look from a student asking me: 'What is an aphorism?' With this question as background, I will firstly provide some perspectives on the history of and a possible definition for the aphorism. Secondly, I will also provide some perspectives on the possible use and value of the aphorism.

Grant (2016:5) guided us to understand that an aphorism uses a limited number of words in order to convey a specific message which is normally a short truth statement which add meaning to life in a very definite way. Originally coined by Hippocrates, and deriving from the Greek apo ('apart') and horos ('border'); 'aphorism', as a word and in meaning, has associations with and reference to the 'horizon' (Grant 2016:8; Snowden 2012:81). The brevity of the message serves as a defining trait mark in the construction and use of the aphorism. 'Brevity of language has the advantage of being able to travel well and quickly, as there is less detail to lose' (Snowden 2012:92).

In this regard, the formulation of tweets on Twitter, serve as an excellent example of the possibility to compose an aphorism. 'Twitter, in its imposed brevity, seems to affirm the aphorism's original meaning: be intelligently succinct' (Gopnik 2019:n.p.). The limited number of characters to be used in the formulation of a tweet (initially 140 and now 280 ), inevitably influence the formulation and scope of the content of Twitter messages.

Speaking directly to the central research concern in this contribution, namely the search for the formulation of a relevant aphoristic theology and ecclesiology, Gopnik's (2019) question is pertinent:

Why is spiritual wisdom found in fragmentary form more reliably than in extended dogma? Why is it that the sayings last, even when their systematic surroundings don't. We know Jesus' parables better than the doctrine of the Trinity, though the latter is far more central to Christianity....(n.p.)

Aphoristic theology implies that the author of the Twitter message has the ability to render specific scriptural and/or theological truths in a concise and impressive manner. ${ }^{4}$ In this regard, it is important to take note of Cheong's (2014:12) research findings regarding the possible value in the use of aphorisms: The formulation of tweets by using amongst other staccato style to quote, extract, remix and recontextualize Scripture, facilitate a strategically shaping of the (re)presentation and interpretation of Scripture via microblogging for example on Twitter. In the ever-evolving digital landscape, this may reveal that conventional words associated with the Christian tradition are used in a creative way in which paradox is for example used to create new meaning.

\section{Strategies for simplicity in composing aphoristic Twitter theology}

I am sensitive to suggesting rigid conventions for the formulation of theological aphorisms. I understand the limitations and restrictions of any platform and/or expression. I would therefore not support a thesis professing that 'tweeting the gospel aphoristically' is the final answer to all the challenges of a

4. A good example of this possibility is found in a contribution by Jackson (2013) which he had written for the South African newspaper Beeld, titled Would Jesus also have tweeted?; and from which I present the following short translated subtraction from the originally piece in Afrikaans:

Think of the following aphorism by Jesus: 'Do not lay aside treasures for yourselves on earth, where moths and rust destroy, and where thieves break in and steal. Instead, lay aside treasures for yourselves in heaven, where neither moth nor rust can destroy, and where thieves do not break in and steal. Where your treasure is, there shall your heart be also'. This can fit easily steal. Where your treasure is, there shall your heart be also.' This can fit easily into a tweet: 'Don't collect treasures on earth where they can be destroyed or stolen. Collect treasures in heaven. Where your treasure is, your heart will be'. It is, precisely, brief and powerful truths of this type that are shared by theologians in tweets nowadays. They are usually conveyed in English, since the conversations extend over geographical boundaries. Furthermore, these are discussions between equals, in which students and professors chat together. There is no place for titles on Twitter. 
contemporary ecclesial ministry. It is, however, a fact that the possibility of creating aphoristic language on a large social media platform such as Twitter presents new possibilities for theological formulation and meaning (Pearson 2015:188). In order to further embody this exciting possibility in a concrete way, I would like to present the following perspectives. In using several tweets originating from the @stephanjoubert account on Twitter, I do not wish to pretend documenting a comprehensive Twitter theology. Rather, using the following examples to express the principles underlying the concept 'simplicity', I want to show how such a Twitter theology can be concretely formulated and embodied.

In looking for concrete illustrations of tweets by @stephanjoubert in which some of the principles of simplicity as indicated by Maeda (2006) are explicitly visible, I have compiled the following reflections, firstly, by referencing the underlying principle of simplicity, then secondly, by portraying the specific tweet specimen as illustration, followed thirdly, by a short personal indication.

\section{- Reduce}

The simplest way to achieve simplicity is through thoughtful reduction ... When in doubt, just remove. But be careful of what you remove. (Maeda 2006:n.p.)

stephan joubert
Tstephanjoubert
1:43 PM - Apr $10,2020 \cdot$ Twitter for iPhone

Source: @stephanjoubert 2020f:n.p.

FIGURE 4: Sun and son.

'At the same time, the very minimal syntax of an aphorism gives it a maximal semantic force. The best aphorism admits an infinitude of interpretation, a hermeneutic inexhaustiblity' (Hui 2019:n.p.). Central to the character of the science of theology is the quest to attempt to formulate truths about God by means of letters, words and sentences. For this reason, the role of language, is so important as building material to express these realities, but in doing so, to also keep the principle of reduction in mind. Innovative and economical language use therefore plays a very important role in construction aphorisms (Figure 4).

\section{- Context}

What lies in the periphery of simplicity is definitely not peripheral ... Our goal is to achieve a kind of enlightened shallowness. (Maeda 2006:n.p.)

Now Good News has a name: Jesus!! And a space: all the way from Betlehem to my own doorstep

10:42 AM · Dec 25, $2020 \cdot$ Twitter for iPhone

Source: @stephanjoubert 2020c:n.p.

FIGURE 5: All the way from Bethlehem to my own doorstep.
In my opinion, the tweet shown in Figure 5 is an extremely apt description for my understanding of theology and, in particular, the nature and character of practical theology. The development in practical theology represents a strong movement from an initial application model to a much more integrated method, in which the holy is found in the everyday (Greenough 2021:134). Understandably, and to express this orientation, the context and the significance of contextuality are important for practical theologians. Practical theology is local, concrete and embodied; and as such my own subjective world needs to be acknowledged (Müller 2009:205). In presenting an auto-ethnographical perspective, I reflect fragments from my own story, by using words and accents that I choose wittingly or unwittingly. Often, my own understanding is caught in my own formulations in seemingly unwitting moments. The presence of God can indeed be traced and described in different contexts. The moment the firmament reaches the earth is thus concretely embodied in contextual descriptions.

\section{- Organize}

Organization makes a system of many appear few ... You will see more, by seeing less. (Maeda 2006:n.p.)

\section{stephan joubert \\ @stephanjoubert}

The cross is empty; the tomb also! Jesus has risen

7:16 AM · Apr 12, $2020 \cdot$ Twitter for iPhone

34 Retweets 152 Likes

Source: @stephanjoubert 2020e:n.p.

FIGURE 6: Gospel message.

I wonder to what extent auto-ethnographical practical theological descriptions have the same ability, in that they challenge the storyteller to express and articulate the deepest meanings in such a way that they must still echo the living world of the reader (Walton 2021:n.p.). In this regard, there are significant interests in popular culture as space for practical theological reflection. Popular culture not only develops at a dizzying speed, because of a number of factors, amongst which the influence of the so-called 4th Industrial Revolution and social media, but it also presents more in-depth questions in terms of man's existential existence. In reflecting on this contextual association and in the quest for the words and language to describe it correctly, aphoristic theological writing is made relevant to readers. In order to organise these dynamic formulations in aphoristic speech elements of paradox, speed, condensation and intention are emphasised in such a way that new meaning is created without the use of the conventional full stop as can be seen in the tweet shown in Figure 6.

\section{- Differences}

Simplicity and complexity need each other.... (Maeda 2006:n.p.) 
I miss mixing with others at church and having coffee afterwards on Sundays. But if these are my main reasons for praying that church own services should start again soon, my understanding of who and what church is needs a serious reset

8:18 AM - May 7, $2020 \cdot$ Twitter for iPhone

Source: @stephanjoubert 2020a:n.p.

FIGURE 7: Reasons for going to church.

In designing the exhibited, a specific creativity in terms of the function of this form, namely the well-known architectonic principle of 'form follows function'. I presume that theological writing often still runs the risk of expressing the opposite and out-dated principle of 'function follows form'. According to this, research could be presented within specific existing frameworks of thought, without understanding its function and whether it will facilitate any change. As far as auto-ethnographical practical theological writing is concerned, I am of the opinion that there is a strong quest for the association with the content of significant academic reflection for one's own life, wherein especially significance is found with other lives (Walton 2021:n.p.). Inevitably, this calls for a re-translation of existing perspectives on, for example, the role of tradition and normativity. The interpretation thereof leads to new, creative, and challenging perspectives as can be seen in Figure 7.

\section{- Simplicity}

Simplicity is about subtracting the obvious, and adding the meaningful ... Simplicity is hopelessly subtle, and many of its defining characteristics are implicit. (Maeda 2006:n.p.)

The cross is not a place for fans to take selfies with Jesus. It is the place where his disciples humble themselves before Him

12:02 PM · Apr 2, $2021 \cdot$ Twitter for iPhone

Source: @stephanjoubert 2020e:n.p.

FIGURE 8: The cross and selfies.

The intention of the tweet shown in Figure 8, with its relatively simple and clean lines, contributes to an impressive unique structure and character of the design. In the on-going project of writing more autoethnographical practical theological contributions, it strikes me that simplicity and accessibility typify the readability of designs and attempts at writing. The reason for this may be that, in simply writing about one's own life and the experience of everyday phenomenon (e.g. like the practice of taking 'selfies'), the most personal aspects echo most generally those of others.

\section{Conclusion}

stephan joubert
Numerophanjoubert
it necessary to have a digital presence in a COVID-19
world. But do not overlook the fact that it is not only
the world that get's transformed by technology, we
are also transformed. Media is never neutral
2:47 PM - Mar 21, 2020 - Twitter for iPhone

Source: @stephanjoubert 2020d:n.p.

FIGURE 9: Social media and the church.

Philosophies come and go, theologies rise and fall, but the aphorism abides. (Hui 2019:n.p.)

Already in my days at high school, my language teacher introduced me to the concept of word economy. With time, I learned that being able to say as much as possible in as few words as possible, is a talent. Coupled with the value gained from, amongst others, paradoxes and poetic language, this has greater and wider significance. Theology and theological aphorisms, in particular, give me room to create with language. I ought to purposely pursue the search for speaking simply. This may start concretely in my life as academic in the sensitive propensity of the number of words I use for arguments. Fewer words can indeed say more.

In the meantime, all of us are exploring unknown territory, on which there is apparently only one sign on a world map: COVID-19. This and its influence on the life of each of us determine how theology and technology ought to be described and practised (Figure 9). In my opinion, this space however provides the potential to develop, formulate, and post a contextually relevant simplistic aphoristic theology possible of changing views and lives. In my view, @stephanjoubert makes a special contribution, in this regard, to both the world of theology and the lifeworld of believers. For this valuable gift in challenging times, I, with many others, owe him my sincere thanks and appreciation.

\section{Acknowledgements Competing interests}

The author declares that he has no financial or personal relationships that may have inappropriately influenced him in writing this article.

\section{Author's contributions}

J.A.v.d.B. is the sole author of this article.

\section{Ethical considerations}

This article followed all ethical standards for research without direct contact with human or animal subjects. 


\section{Funding information}

This research received no specific grant from any funding agency in the public, commercial or not-for-profit sectors.

\section{Data availability}

Data sharing is not applicable to this article as no new data were created or analysed in this study.

\section{Disclaimer}

The views and opinions expressed in this article are those of the author and do not necessarily reflect the official policy or position of any affiliated agency of the author.

\section{References}

Browning, D.S., 1991, A fundamental practical theology, descriptive and strategic proposals, Fortress Press, Minneapolis, MN.

Cheong, P.H., 2014, 'Tweet the message? Religious authority and social media innovation', Journal of Religion, Media and Digital Culture 3(1), 1-19. https://doi. org/10.1163/21659214-90000059

Gopnik, A., 2019, 'The art of the aphorism, Why are these fragments of wisdomempirical or mystical, funny or profound-such an enduring form?', The New Yorker,
viewed 11 December 2020, from https://www.newyorker.com/ magazine/2019/07/22/the-art-of-aphorism.

Grant, B., 2016, The aphorism and other short forms, Routledge, New York, NY

Greenough, C., 2021, 'From biblical text to Twitter, teaching biblical studies in the Zeitgeist of \#MeToo', The Journal of Feminist Studies in Religion 37(1), 133-135. https://doi.org/10.2979/jfemistudreli.37.1.10

Hendriks, H.J., 2004, Studying congregations in Africa, Lux Verbi BM, Wellington.

Holt, N.L., 2003, 'Representation, legitimation, and autoetnography: An autoetnographic writing story', International Journal of Qualitative Methods 2(1), 18-28. https://doi.org/10.1177/160940690300200102

Hui, A., 2019, A theory of the aphorism, from Confucius to Twitter, Princeton University Press, Princeton, NJ.

Jackson, N., 2013, 'Would Jesus also have tweeted?', Beeld, 06 Junie [translation from the original Afrikaans].
Joubert, S.J., 2014, personal e-mail communication, 14 July 2014.

Maeda, J., 2006, The laws of simplicity, MIT, Cambridge, MA.

Müller, J.C., 2009, 'Transversal rationality as a practical way of doing interdisciplinary work, with HIV and Aids as a case study', Practical Theology in South Africa 24(2), 199-228.

Müller, J.C. \& Maritz, B., 1998, 'Die waarde van metafore binne die hermeneutiespastorale sisteem', Praktiese Teologie in Suid-Afrika 13(1), 64-71.

Nouwen, H.J.M., 1976, The Genesee diary: Report from a trappist monastery, Doubleday, New York, NY.

Pearson, C., 2015, 'Twittering the gospel', International Journal of Public Theology 9(2), 176-192. https://doi.org/10.1163/15697320-12341391

Snowden, C., 2012, 'From epigrams to tweets', Asiatic 6(2), 81-95.

Van den Berg, J.A., 2018, 'Tweeting God: A practical theological analysis of the communication of Christian motifs on Twitter', Unpublished PhD thesis, University of Queensland.

Walton, H., 2021, What is autoethnograhpy and why does it matter for theological reflection, ANVIL, vol. 36, no. 1, viewed 22 March 2021, from https:// churchmissionsociety.org/resources/what-is-autoethnography-theologicalchurchmissionsociety.org/resources/what-is-au
reflection-heather-walton-anvil-vol-36-issue-1/.

@stephanjoubert, 2020a, I miss mixing with others and having coffee afterwards, viewed 11 December 2020, from https://twitter.com/stephanjoubert/ status/1258280094981926912

@stephanjoubert, 2020b, Living respectfully in a time of Corona, viewed 02 February 2021, from https://twitter.com/stephanjoubert/status/1242694111230115841

@stephanjoubert, 2020c, Now good news has a name: Jesus!!, viewed 06 January 2021, from https://twitter.com/stephanjoubert/status/1342390198630567937

@stephanjoubert, 2020d, Numerous churches invade social media, viewed on 14 February 2021, from https://twitter.com/stephanjoubert/status/12413456 55668441090

@stephanjoubert, 2020e, The cross is empty; The tomb also, viewed 11 December 2020, from https://twitter.com/stephanjoubert/status/1249204643571339264

@stephanjoubert, 2020f, The sun cannot shine when the son has died, viewed 28 January 2020, from https://twitter.com/stephanjoubert/status/12485772889 72767232

@stephanjoubert, 2021a, Jesus follower, Catalyst, Author: Part of the amazing echurch/ekerk \& Joubert tribes, viewed 02 April 2021, from https://twitter.com/ stephanjoubert?lang=en

@stephanjoubert, 2021b, The biggest coup in history, viewed 22 March 2021, from https://twitter.com/stephanjoubert/status/1373504046158450688

@stephanjoubert, 2021c, The cross is not a place for fans to takes selfies with Jesus, viewed 02 April 2021, from https://twitter.com/stephanjoubert/status/13779244 05951627264 